\title{
Ultrasound imaging for lumbar punctures and epidural catheterisations: systematic review and meta-analysis
}

\author{
(ब) (1) OPEN ACCESS
}

\author{
Furqan Shaikh research fellow ${ }^{1}$, Jack Brzezinski clinical fellow ${ }^{1}$, Sarah Alexander assistant \\ professor $^{1}$, Cristian Arzola assistant professor ${ }^{2}$, Jose C A Carvalho professor ${ }^{2}$, Joseph Beyene \\ associate professor ${ }^{3}$, Lillian Sung associate professor ${ }^{1}$
}

${ }^{1}$ Division of Haematology and Oncology, Hospital for Sick Children and University of Toronto, Toronto, ON, Canada M5G 1X8; ${ }^{2}$ Department of Anaesthesia and Pain Management, Mount Sinai Hospital and University of Toronto, Toronto, ON, Canada; ${ }^{3}$ Department of Clinical Epidemiology and Biostatistics, McMaster University, Hamilton, ON, Canada

\begin{abstract}
Objective To determine whether ultrasound imaging can reduce the risk of failed lumbar punctures or epidural catheterisations, when compared with standard palpation methods, and whether ultrasound imaging can reduce traumatic procedures, insertion attempts, and needle redirections.

Design Systematic review and meta-analysis of randomised controlled trials.

Data sources Ovid Medline, Embase, and Cochrane Central Register of Controlled Trials up to May 2012, without restriction by language or publication status.

Review methods Randomised trials that compared ultrasound imaging with standard methods (no imaging) in the performance of a lumbar puncture or epidural catheterisation were identified.

Results 14 studies with a total of 1334 patients were included (674 patients assigned to the ultrasound group, 660 to the control group). Five studies evaluated lumbar punctures and nine evaluated epidural catheterisations. Six of 624 procedures conducted in the ultrasound group failed; 44 of 610 procedures in the control group failed. Ultrasound imaging reduced the risk of failed procedures (risk ratio 0.21 (95\% confidence interval 0.10 to 0.43 ), $P<0.001$ ). Risk reduction was similar when subgroup analysis was performed for lumbar punctures (risk ratio 0.19 (0.07 to 0.56$), P=0.002$ ) or epidural catheterisations ( 0.23 ( 0.09 to $0.60), P=0.003)$. Ultrasound imaging also significantly reduced the risk of traumatic procedures (risk ratio 0.27 ( 0.11 to 0.67$), P=0.005)$, the number of insertion attempts (mean difference $-0.44(-0.64$ to -0.24$)$, $\mathrm{P}<0.001$ ), and the number of needle redirections (mean difference -1.00 $(-1.24$ to -0.75$), P<0.001)$.
\end{abstract}

Conclusions Ultrasound imaging can reduce the risk of failed or traumatic lumbar punctures and epidural catheterisations, as well as the number of needle insertions and redirections. Ultrasound may be a useful adjunct for these procedures.

\section{Introduction}

Lumbar punctures and epidural catheterisations are common procedures used to access the subarachnoid and epidural spaces. Lumbar punctures are used for diagnostic sampling of the cerebrospinal fluid to evaluate for suspected infections of the central nervous system, haemorrhage, neoplasm, or inflammatory disorders, as well as for delivering therapeutic agents to the intrathecal space. ${ }^{1}$ Epidural catheterisations provide regional anaesthesia and analgesia during childbirth or surgical procedures. $^{2}$ A national audit project estimated that over 293 000 epidurals and 325000 subarachnoid blocks are performed each year in the United Kingdom. ${ }^{3}$

A failure to obtain diagnostic samples or to achieve correct placement can occur. Failed procedures result in the loss of diagnostic information, ${ }^{4}$ inability to deliver treatment, or inadequate analgesia. Traumatic lumbar punctures confound the interpretation of diagnostic tests on cerebrospinal fluid. ${ }^{56}$ In patients with acute lymphoblastic leukaemia, an initial traumatic lumbar puncture with blasts in the cerebrospinal fluid impairs the diagnostic utility of the procedure and is associated with an increased risk of relapse..$^{7-10}$ When procedures are difficult, repeated needle insertions and redirections increase the pain and discomfort experienced by the patient. ${ }^{11}$

The performance of lumbar punctures and epidural catheterisations relies primarily on the palpation of anatomical landmarks, which might be obscured in the context of obesity, oedema, or anatomical variation. Other important aspects of the procedure, such as the angle of needle progression and the 
distance from the skin to the target space, cannot be assessed by palpation and rely on the skill of the operator. Similar to the experience with peripheral nerve blocks ${ }^{12}$ and central vascular access, ${ }^{13}{ }^{14}$ it has been hypothesised that the ability to visualise the relevant anatomy of the procedure may aid in its success. ${ }^{2}{ }^{15}$ Consequently, interest has been growing in the use of ultrasound imaging as an adjunct to lumbar punctures or epidural catheterisations. Pre-procedure ultrasound scanning can identify an intended vertebral interspace level, the midline of the spine, the optimal puncture point, the optimal angle for needle insertion, and the depth to the spinal canal. ${ }^{16}{ }^{17}$ Real time or dynamic scanning can visualise the progression of the needle and the injected drug entering the desired space. ${ }^{18}$ Ultrasound is relatively cheap, readily available at the point of care, compact, and involves no radiation.

Many randomised controlled trials have been performed to evaluate ultrasound imaging for lumbar punctures or epidural catheterisations. However, almost all trials were underpowered to show differences in the most clinically important outcomes, such as failed procedures. Although there have been several qualitative or systematic reviews of ultrasound in the context of regional anaesthesia, ${ }^{12}{ }^{19-21}$ there is no published meta-analysis of randomised controlled trials evaluating ultrasound imaging for these procedures. We hypothesised that by synthesising all randomised controlled trials, a meta-analysis would provide increased power and more precise estimates of the effect of ultrasound imaging for lumbar punctures and epidural catheterisations. Our primary objective was to determine whether ultrasound imaging reduces the risk of failed lumbar punctures or epidural catheterisations in adults or children undergoing these procedures, by comparison with standard palpation methods. Our secondary objectives were to determine whether ultrasound imaging affects traumatic procedures, the number of insertion attempts, the number of needle redirections, and the time taken to perform the procedure.

\section{Methods}

\section{Data sources and searches}

We developed a protocol for review and followed PRISMA (preferred reporting items for systematic reviews and meta-analyses) guidelines. ${ }^{22}$ The study was not registered. We performed comprehensive searches for relevant trials using the Ovid platform in Medline (from 1948 to May 2012), Embase (from 1980 to May 2012), and the Cochrane Central Register of Controlled Trials (to the second quarter of 2011), without restriction by language or publication status. The search strategy included the following medical subject heading terms: "ultrasonography," "spinal puncture," "epidural analgesia," "spinal anaesthesia," and "obstetrical anaesthesia." We also included multiple synonyms, abbreviations, and related keywords for each of these terms. The set was limited to clinical trials, observational studies, or diagnostic studies (search strategy available in the web table). We also examined the reference lists of retrieved original and review articles.

\section{Study selection}

Randomised or quasi-randomised trials were included if they did all of the following:

- Randomly assigned patients undergoing lumbar punctures or epidural catheterisations in the lumbar region

- Compared ultrasound imaging (as either pre-procedure landmarking or real time scanning) with a non-imaging technique such as palpation or loss of resistance

\section{- Reported at least one of our primary or secondary} outcomes.

The loss of resistance technique identifies the epidural space by the sudden change in pressure on the piston of a syringe as the needle enters the space. We excluded studies of procedures involving the peripheral nerves or the caudal, paravertebral, radicular, or plexus regions.

Two investigators (FS and JB) independently screened the titles and abstracts of articles identified by the search strategy. Articles thought to be potentially eligible were obtained in full and each of these articles was assessed for eligibility by both reviewers. Discrepancies were resolved by consensus.

\section{Outcome measures and definitions}

Spinal anaesthesia was classified as a lumbar puncture, because it involves accessing the subarachnoid space. Combined spinal and epidural catheterisation was classified as an epidural catheterisation, because the first task of the combined procedure is to identify the epidural space.

The outcomes of interest, in order of importance, were failed procedures, traumatic procedures, number of insertion attempts, number of needle redirections, and time taken to perform the procedure. We defined these outcomes a priori, but used each study's definitions if they were reasonable and similar to ours. In general, a failed lumbar puncture was defined as one without the return of cerebrospinal fluid. A failed epidural catheterisation was defined as inability to place the catheter, a requirement for additional intraoperative analgesia, or a requirement to replace the epidural catheter. In short, a procedure was considered to have failed if the intended objective of the procedure, whether to collect a diagnostic sample or to provide analgesia, could not be fulfilled. A traumatic lumbar puncture or epidural catheterisation was defined as visible blood aspiration or a red blood cell count in the cerebrospinal fluid above an appropriately defined threshold.

Studies variably defined insertion attempts - as either "redirection" of the needle (without further skin puncture), or "reinsertion" of the needle (a withdrawal and new puncture through the skin). Because a reinsertion implies a greater degree of adjustment needed for correct needle placement, it is a more substantial outcome than a redirection. We attempted to classify, wherever possible, the study's definition of an "attempt" into either a redirection or a reinsertion. We assumed that each bony contact led to a redirection. If the meaning was unclear, we classified an attempt as a redirection alone, to remain conservative in the estimated benefit of ultrasound imaging.

\section{Data extraction and quality assessment}

Two investigators (FS and JB) independently and in duplicate assessed the risk of bias at the study level, using the CLEAR-NPT tool (a checklist to evaluate a report of a non-pharmacological trial). ${ }^{23}$ The CLEAR-NPT was created specifically to measure the quality of reports of randomised controlled trials assessing non-pharmacological treatments such as surgeries or devices. Since our outcomes of interest were assessable instantaneously, participant adherence, withdrawals, and intention to treat analysis were not relevant. We thus modified the instrument by reporting the domains meaningful for studies of ultrasound imaging.

We focused on randomisation, allocation concealment, blinding, outcome reporting, details of the intervention, and operator experience or skill. The term "operator" here refers to the person performing the needle procedure, not the person performing the 
ultrasound imaging (if not the same individual). We categorised experience and skill as being inadequate if the operators were junior residents within one year of their residency training. If blinding was not used, we also included a domain on whether the same operator was assigned to both groups, which could create a risk for performance bias or an unconscious incentive to show a benefit of ultrasound imaging. The quality of each domain was presented as adequate, inadequate, or unstated or unclear. Disagreements were resolved by consensus.

The same two investigators (FS and JB) independently and in duplicate abstracted data from the trials using a standardised form. They sought the following information from each source article: year of publication, country of study, population and setting, type of procedure (lumbar punctures $v$ epidural catheterisation), type of ultrasound imaging (pre-procedure $v$ real time), operator characteristics, and type of ultrasound device. If data were not available for validity assessment or outcomes, study authors were contacted to obtain further information.

\section{Data synthesis and analysis}

Because of differences in how summary statistics for continuous outcomes were reported, we made the following assumptions to facilitate data synthesis: the mean can be approximated by the median, the range contains six standard deviations, and the interquartile range contains 1.35 standard deviations. When no measure of dispersion was reported, the outcome was not included in the synthesis.

We analysed dichotomous outcome data with the Mantel-Haenszel method and used risk ratio as the effect measure, where a risk ratio less than 1 suggests that ultrasound imaging is better than non-imaging techniques. To account for rare events, we also conducted a sensitivity analysis using the Peto method, where an odds ratio less than 1 suggests that ultrasound imaging is better than non-imaging techniques. We calculated the absolute risk reduction as the difference between the event rates in the control arm and the ultrasound arm, and calculated the number needed to treat as the inverse of the absolute risk reduction. We expressed the effect on continuous outcome variables as the mean difference, where a mean difference less than 0 indicates that ultrasound imaging required fewer needle insertions or redirection attempts than the control procedure.

We summarised the findings using a random effects model, which allows consideration of variations between studies. We looked for heterogeneity among the trials using standard methods and calculated the $\mathrm{I}^{2}$ index, which describes the percentage of variability in the effect estimates that are due to heterogeneity beyond sampling error. ${ }^{24}$

We conducted planned subgroup analyses for the effect of ultrasound imaging by type of procedure (lumbar punctures $v$ epidural catheterisation), specialty of operator (emergency physician $v$ anaesthetist), expected difficulty (studies of patients with a higher expected risk of difficult procedures $v$ studies of unselected patients), the experience level of the operator performing the spinal procedure (high $v$ low), and whether the same operator was assigned to both groups. Subgroup analyses were conducted for each outcome whenever more than one study with an estimable effect was available per subgroup.

We assessed publication bias by visual inspection of a funnel plot of the effect size (that is, risk ratio) versus its precision (that is, standard error) for each outcome if at least 10 studies were available. We assumed that asymmetry in the lower right hand corner of the funnel plot indicated that small trials with negative outcomes were not represented in the literature. The potential effect of such missing trials was evaluated using the trim and fill technique. ${ }^{24}$

Agreement between the two reviewers regarding inclusion of articles and each domain of study validity was examined using the $\kappa$ statistic. We performed analyses using Review Manager (RevMan 5.1, Cochrane Collaboration) and SAS (version 9.3).

\section{Results}

Figure $1 \Downarrow$ illustrates the flow diagram of trial identification and selection. From a total of 2494 individual records, we identified and included 14 randomised controlled trials of ultrasound imaging in the systematic review. ${ }^{25-38}$ Eleven studies were published as full articles and three published as abstracts. ${ }^{29} 3638$ The $\kappa$ score for agreement for study inclusion was 0.94 (95\% confidence interval 0.84 to 1.00 ).

Table $1 \Downarrow$ lists characteristics of the 14 trials. In total, 1334 patients were randomly assigned to receive ultrasound imaging (674 patients) or to the control group (660 patients). All patients in the control arm received the standard procedure with manual palpation or loss of resistance (or both), but no form of imaging.

Seven trials reported outcomes for obstetric epidural anaesthesia, two for surgical epidural anaesthesia, one for spinal anaesthesia, and four for lumbar punctures in the emergency room. Therefore, in total, nine studies used ultrasound imaging for epidural catheterisations and five for lumbar punctures. Eleven studies used a pre-procedure landmarking approach, two studies used real time ultrasound visualisation, and one study used both techniques. There was one paediatric trial. ${ }^{30}$ In all studies, the ultrasound imaging and landmarking was performed by a study investigator who had adequate expertise in the technique. For the ultrasound groups, the lumbar puncture or epidural catheterisation was subsequently performed by either the same investigator, or by another operator using information obtained by the ultrasound.

Summary of the risk of bias is presented in table $2 \Downarrow$. Only one study was double blinded (both the operator and patients). In this study, ${ }^{31}$ blinding of the operator was achieved by marking sites of insertion determined by ultrasound or palpation with ultraviolet ink visible under a special light. Therefore, only one site was known to the lumbar puncture operators based on their random assignment to either the ultrasound arm or the control arm. No other study blinded either the operator or the patient. Most of the earlier studies were unclear in their description of the methods used for sequence generation or allocation concealment. All of the studies were described as being randomised.

The primary outcome, procedure failure, included data from 12 studies and 1234 randomised patients. Table $3 \Downarrow$ and figure $2 \Downarrow$ show that the use of ultrasound imaging reduced the risk of failed procedures (risk ratio 0.21 (95\% confidence interval 0.10 to 0.43$), \mathrm{P}<0.001$ ). There were six failed procedures of 624 in the ultrasound group compared with 44 failed procedures of 610 in the control group. The absolute risk reduction in the risk of failed procedures was 0.063 , resulting in a number needed to treat of 16 ultrasound guided procedures to reduce one failure.

Table 3 summarises the secondary outcomes. Ultrasound imaging reduced the risk of traumatic procedures with a risk ratio of 0.27 ( $95 \%$ confidence interval 0.11 to $0.67, \mathrm{P}=0.005$ ), an absolute risk reduction of 0.059 and a number needed to treat of 17. Ultrasound imaging also reduced the number of insertion attempts by a mean difference of $-0.44(-0.64$ to -0.24 , $\mathrm{P}<0.001)$ and the number of needle redirections by a mean 
difference of -1.00 per procedure $(-1.24$ to $-0.75, \mathrm{P}<0.001)$. The time taken to perform the ultrasound imaging procedures could not be meta-analysed because the time periods reported were too heterogeneous across studies (for example, studies variably included or excluded preparation time or needle procedure time).

In the sensitivity analysis of dichotomous outcomes using the Peto method, ultrasound imaging reduced the odds of a failed procedure (odds ratio 0.20 (95\% confidence interval 0.11 to $0.36), \mathrm{P}<0.001)$ and the odds of a traumatic procedure $(0.28$ (0.13 to 0.61$), \mathrm{P}=0.001)$.

Table $4 \Downarrow$ presents the subgroup analyses. The effect of ultrasound imaging on reduction of failed lumbar punctures (risk ratio $0.19,95 \%$ confidence interval 0.07 to $0.56, \mathrm{P}=0.002$ ) and epidural catheterisations $(0.23,95 \%$ confidence interval 0.09 to $0.60, \mathrm{P}=0.003$ ) was similar ( $\mathrm{P}=0.92$ for interaction). Subgroup analysis showed that the benefit of ultrasound imaging in reducing the mean number of insertion attempts was significantly larger for lumbar punctures than for epidural catheterisations. Another subgroup analysis suggested that the reduction in the mean number of insertion attempts may be larger for patients selected for presumed difficult procedures than for unselected patients, but the effect did not reach statistical significance. For all other subgroup analyses, effect estimates were not significantly different.

A funnel plot of the risk ratio for failed procedures versus standard errors was asymmetric because of the large effect sizes of two studies ${ }^{273}$ and suggested that the results of small negative trial(s) may not have been published (plot not shown). To assess the effect of this potential publication bias on our point estimate of the risk ratio, we performed a second analysis that excluded the results of these two studies. The pooled estimate of the risk ratio for the ten remaining studies was 0.24 (95\% confidence interval 0.11 to 0.52 ). After we added back the two studies, together with two hypothetical counterpart studies of equal sizes but opposite effects, the recalculated risk ratio was 0.35 (0.15 to 0.85 ). Therefore, the possible exclusion of small negative trial(s) from this analysis did not change the conclusion of the primary objective. Funnel plots were not evaluated for secondary objectives because no other outcome had ten or more available studies.

\section{Discussion}

Our meta-analysis shows that ultrasound imaging can reduce the risk of failed or traumatic lumbar punctures and epidural catheterisations as well as the number of insertion attempts and needle redirections. The most likely explanation for these findings is that ultrasound visualisation of the relevant anatomy provides the operator with information regarding the midline of the spine, the optimal vertebral level, and the depth to the desired space. Ultrasound thus supplements anatomical information available by palpation. The advantages of ultrasound imaging appeared consistent across multiple subgroup analyses. Ultrasound could therefore be a useful adjunct for lumbar punctures and epidural catheterisations. In particular, clinicians working in settings where these procedures are commonly performed (obstetric anaesthesia and emergency rooms) or where failure is associated with particularly negative consequences (paediatric oncology) should consider utilising ultrasound imaging.

\section{Strengths and limitations}

The strengths of this review include broad eligibility criteria that did not exclude studies based on publication status or language. This allowed the review to be representative of the available literature. Furthermore, we hypothesised a priori that ultrasound imaging would have a similar effect in both lumbar punctures and epidural catheterisations and that both types of procedures could be reasonably pooled in a meta-analysis. The resulting data supported this hypothesis. By combining the two types of procedures, we were able to evaluate the effect of ultrasound imaging in both groups and achieved a larger sample size and greater power for synthesis.

Our meta-analysis has several limitations. Similar to many meta-analyses, it is limited by the methodological quality and outcome reporting of its component studies. Only one study fulfilled all seven quality measures that we used to evaluate validity. ${ }^{31}$ This was the only double blind study, and no other study attempted to blind patients. Although blinding the operator in ultrasound imaging trials is logistically difficult, there is little reason that patients cannot be blinded to the assigned treatment by use of a sham ultrasound application. Secondly, in all trials, the individuals performing the ultrasound imaging were study investigators who generally had high levels of experience and special interest in the technique. Many of the studies (seven of 14) were in the setting of obstetric anaesthesia, and thus included a patient population composed of young, collaborating, healthy women. These features might limit the external validity of our findings. Thirdly, other important complications of these procedures, such as postdural puncture headaches or pain during the procedure, were not often reported and could not be synthesised. Time taken to perform the procedure, one of our intended secondary outcomes, was defined and measured differently across studies and thus could not be meta-analysed. None of the studies included a cost effectiveness analysis.

\section{Comparison with other studies}

Some previous narrative reviews and systematic qualitative reviews have suggested a potential benefit for ultrasound imaging in the context of regional anaesthesia of the spine, ${ }^{12}{ }^{19-21}$ but none performed a quantitative synthesis. A guideline by the National Institute for Health and Clinical Excellence on ultrasound guided epidural catheterisation similarly concluded that ultrasound might be helpful in achieving correct epidural placement, but that evidence was limited. ${ }^{39}$ Our meta-analysis is the first study to quantitatively evaluate the effect on failed procedures, which is the most clinically significant outcome. Nearly all the component randomised controlled trials were underpowered for this outcome and could not show a significant beneficial effect. Many studies individually concluded that ultrasound had no effect on the rate of failed procedures. However, when pooled together in meta-analysis, a clinically and statistically significant effect clearly emerged.

Another imaging technique, fluoroscopy, is often used as a rescue modality after failed lumbar punctures. ${ }^{40}{ }^{41}$ However, ultrasound has important advantages compared with fluoroscopy. Fluoroscopy is expensive, not readily available or portable, requires multiple operators, and involves radiation exposure. ${ }^{42} 43$ Consequently, we believe that a focus is warranted on ultrasound imaging rather than fluoroscopy for these procedures.

\section{Implications for practice and research}

Future studies should determine the optimal way to incorporate ultrasound imaging for lumbar punctures and epidural catheterisations into clinical practice. Because the baseline rate of failed procedures was low even when ultrasound was not used, it is unclear whether ultrasound imaging should be used for all lumbar punctures and epidural catheterisations. Perhaps 
it will be best used in a risk directed manner for patients anticipated to have difficult procedures, or as a rescue modality after failed procedures. This question should be further investigated. The best approach will probably vary across different settings depending on the volume of procedures, baseline rate of failure, availability of proficiency in the ultrasound technique, and cost of obtaining the required training and equipment. Additional pragmatic randomised controlled trials of high methodological quality would be of benefit in further validating these results.

Future research should also focus on the cost effectiveness of using ultrasound imaging for these procedures. ${ }^{15}$ The cost includes the expense of purchasing and maintaining the equipment and obtaining training. In smaller institutions, equipment can be shared among different departments. Point-of-care ultrasound is already used to provide image guidance across a wide range of other medical and surgical procedures. ${ }^{15}$ Furthermore, the cost of ultrasound imaging is likely to rapidly decline in the future, as ultrasound technology becomes less expensive and more compact, and proficiency with ultrasound becomes more ubiquitous among clinicians. Some medical schools now include ultrasound education within their curriculums and provide students with portable machines to be used during their rotations. ${ }^{44-46}$ If such trends continue, both ultrasound skills and equipment will become increasingly available in routine clinical settings. Based on the results of this meta-analysis, lumbar punctures and epidural catheterisations can be added to the growing list of medical procedures that could benefit from ultrasound imaging.

We thank Elizabeth Uleryk for her expert assistance with the literature search and Jisun Kim for her assistance in translating non-English papers.

Contributors: Both FS and JB contributed as co-first authors to this work. All authors contributed to the conception of the study. FS, JB, and LS were responsible for the study design, data collection, statistical analysis, and manuscript drafting. SA, CA, JCAC, and JB were responsible for manuscript drafting, providing important intellectual content throughout the manuscript's production, and approval of the final version to be published. FS is the guarantor.

Funding: FS is supported by a research fellowship from the Pediatric Oncology Group of Ontario research unit. LS is supported by a New Investigator Award from the Canadian Institutes of Health Research. The funders had no role in the design, execution, and writing up of the study. All researchers were independent from funders.

Competing interests: All authors have completed the Unified Competing Interest form at www.icmje.org/coi_disclosure.pdf (available on request from the corresponding author) and declare: support from the Pediatric Oncology Group of Ontario and the Canadian Institutes of Health Research for the submitted work; no financial relationships with any organisations that might have an interest in the submitted work in the previous 3 years; no other relationships or activities that could appear to have influenced the submitted work.

Ethics approval: Ethics approval not required.

Data sharing: Full data in RevMan files available from corresponding author on request.

Straus SE, Thorpe KE, Holroyd-Leduc J. How do I perform a lumbar puncture and analyze the results to diagnose bacterial meningitis? JAMA 2006;296:2012-22.

2 Carvalho JCA. Ultrasound-facilitated epidurals and spinals in obstetrics. Anesthesiol Clin 2008;26:145-58, vii-viii.

3 Cook TM, Counsell D, Wildsmith JAW. Major complications of central neuraxial block: report on the third national audit project of the Royal College of Anaesthetists. Br J Anaesth 2008;102:179-90

4 Shah KH, Richard KM, Nicholas S, Edlow JA. Incidence of traumatic lumbar puncture. Acad Emerg Med 2003;10:151-4.
5 Heasley DC, Mohamed MA, Yousem DM. Clearing of red blood cells in lumbar puncture does not rule out ruptured aneurysm in patients with suspected subarachnoid hemorrhage but negative head CT findings. Am J Neuroradiol 2005;26:820-4.

6 Mazor SS, McNulty JE, Roosevelt GE. Interpretation of traumatic lumbar punctures: who can go home? Pediatrics 2003;111:525-8.

7 Gajjar A, Harrison PL, Sandlund JT, Rivera GK, Ribeiro RC, Rubnitz JE, et al. Traumatic lumbar puncture at diagnosis adversely affects outcome in childhood acute lymphoblastic leukemia. Blood 2000;96:3381-4.

8 Burger B, Zimmermann M, Mann G, Kuhl J, Loning L, Riehm H, et al. Diagnostic cerebrospinal fluid examination in children with acute lymphoblastic leukemia: significance of low leukocyte counts with blasts or traumatic lumbar puncture. $J$ Clin Oncol 2003;21:184-8.

9 Te Loo DM, Kamps WA, Van Der Does-Van Den Berg A, Van Wering ER, De Graaf SS. Prognostic significance of blasts in the cerebrospinal fluid without pleiocytosis or a traumatic lumbar puncture in children with acute lymphoblastic leukemia: experience of the Dutch Childhood Oncology Group. J Clin Oncol 2006;24:2332-6.

10 Pui CH, Campana D, Pei D, Bowman WP, Sandlund JT, Kaste SC. Treating childhood acute lymphoblastic leukemia without cranial irradiation. N Engl J Med 2009;360:2730-41

11 Seeberger MD, Kaufmann M, Staender S, Schneider M, Scheidegger D. Repeated dural punctures increase the incidence of postdural puncture headache. Anesth Analg 1996;82:302-5.

12 Liu SS, Ngeow JE, YaDeau JT. Ultrasound-guided regional anesthesia and analgesia: a qualitative systematic review. Region Anesth Pain M 2009;34:47-59.

13 Hind D, Calvert N, McWilliams R, Davidson A, Paisley S, Beverley C, et al. Ultrasonic locating devices for central venous cannulation: meta-analysis. BMJ 2003;327:361.

14 Kumar A, Chaun A. Ultrasound guided vascular access: efficacy and safety. Best Pract Res Clin Anaesthesiol 2009;23:299-311.

15 Moore CL, Copel JA. Point-of-care ultrasonography. N Engl J Med 2011;364:749-57.

16 Stiffler KA, Jwayyed S, Wilber ST, Robinson A. The use of ultrasound to identify pertinent landmarks for lumbar puncture. Am J Emerg Med 2007;25:331-4.

17 Arzola C, Davies S, Rofaeel A, Carvalho JCA. Ultrasound using the transverse approach to the lumbar spine provides reliable landmarks for labor epidurals. Anesth Analg 2007:104:1188-92, tables of contents.

18 Tran D, Kamani AA, Al-Attas E, Lessoway VA, Massey S, Rohling RN. Single-operator real-time ultrasound-guidance to aim and insert a lumbar epidural needle. Can J Anaesth 2010;57:313-21

19 Grau T, Conradi R, Martin E, Motsch J. [Ultrasound and local anaesthesia. Part III: ultrasound and neuroaxial local anaesthesia]. Anaesthesist 2003;52:68-73.

20 Perlas A. Evidence for the use of ultrasound in neuraxial blocks. Reg Anesth Pain Med 2010;35(2 suppl):S43-6.

21 Tsui BCH, Suresh S. Ultrasound imaging for regional anesthesia in infants, children, and adolescents: a review of current literature and its application in the practice of neuraxial blocks. Anesthesiology 2010;112:719-28.

22 Moher D, Liberati A, Tetzlaff J, Altman DG. Preferred reporting items for systematic reviews and meta-analyses: the PRISMA statement. BMJ 2009;339:332-6.

23 Boutron I, Moher D, Tugwell P, Giraudeau B, Poiraudeau S, Nizard R, et al. A checklist to evaluate a report of a nonpharmacological trial (CLEAR NPT) was developed using consensus. J Clin Epidemiol 2005;58:1233-40.

24 Higgins JPT, Green S, eds. Cochrane handbook for systematic reviews of interventions. Version 5.1.0 (updated March 2011). Cochrane Collaboration, 2011.www.cochranehandbook.org.

25 Grau T, Leipold RW, Conradi R, Martin E. Ultrasound control for presumed difficult epidural puncture. Acta Anaesthesiol Scand 2001;45:766-71.

26 Grau T, Leipold RW, Conradi R, Martin E, Motsch J. Ultrasound imaging facilitates localization of the epidural space during combined spinal and epidural anesthesia. Reg Anesth Pain Med 2001;26:64-7.

27 Grau T, Leipold RW, Conradi R, Martin E, Motsch J. Efficacy of ultrasound imaging in obstetric epidural anesthesia. J Clin Anesth 2002;14:169-75.

28 Grau T, Leipold RW, Fatehi S, Martin E, Motsch J. Real-time ultrasonic observation of combined spinal-epidural anaesthesia. Eur J Anaesthesiol 2004;21:25-31.

29 Pisupati D, Heyming TW, Lewis RJ, Peterson MA. Effect of ultrasonography localization of spinal landmarks on lumbar punctures in the emergency department. Ann Emerg Med 2004;44:s83.

30 Willschke H, Marhofer P, Bosenberg A, Johnston S, Wanzel O, Sitzwohl C, et al. Epidural catheter placement in children: comparing a novel approach using ultrasound guidance and a standard loss-of-resistance technique. Br J Anaesth 2006;97:200-7.

31 Nomura JT, Leech SJ, Shenbagamurthi S, Sierzenski PR, O'Connor RE, Bollinger M, et al. A randomized controlled trial of ultrasound-assisted lumbar puncture. $J$ Ultrasound Med 2007;26:1341-8.

32 Lee WS, Jeong WJ, Yi HY, Ryu S, Lee JW, Kim SW, et al. The usefulness of ultrasound-assisted lumbar puncture on adult patients in the emergency center: comparison with classic lumbar puncture. J Korean Soc Emerg Med 2008;19:562-8.

33 Cho YC, Koo DH, Oh SK, Jeong WJ, Lee WS, Ryu S, et al. Comparison of ultrasound-assisted lumbar puncture with lumbar puncture using palpation of landmarks in aged patients in an emergency center. J Korean Soc Emerg Med 2009;20:304-9.

34 Vallejo MC, Phelps AL, Singh S, Orebaugh SL, Sah N. Ultrasound decreases the failed labor epidural rate in resident trainees. Int J Obstet Anesth 2010;19:373-8.

35 Chin KJ, Perlas A, Chan V, Brown-Shreves D, Koshkin A, Vaishnav V. Ultrasound imaging facilitates spinal anesthesia in adults with difficult surface anatomic landmarks. Anesthesiology 2011;115:94-101.

36 Gnaho A, Cirodde A, Lemarec C, Chazalon P, Jost D, Gentili ME. Ultrasound guided epidural anesthesia versus standard loss of resistance technique in obese patients. Eur $J$ Pain Suppl 2011;5:102.

37 Kawaguchi Rl, Yamauchi M, Sugino S, Yamakage M. Ultrasound-aided ipsilateral-dominant epidural block for total hip arthroplasty: a randomised controlled single-blind study. Eur $J$ Anaesthesiol 2011;28:137-40.

38 Fogel ST, Hill JL, Davis W, Bin G, Michael NA. Pre procedure ultrasound in obstetric neuraxial analgesia: when is it worth the effort. Region Anesth Pain Med 2011;36:508-20.

39 National Institute for Health and Clinical Excellence. Guideline: ultrasound-guided catheterisation of the epidural space. NICE, 2008.

40 Yu SD, Chen MY, Johnson AJ. Factors associated with traumatic fluoroscopy-guided lumbar punctures: a retrospective review. Am J Neuroradiol 2009;30:512-5.

41 Eskey CJ, Ogilvy CS. Fluoroscopy-guided lumbar puncture: decreased frequency of traumatic tap and implications for the assessment of CT-negative acute subarachnoid hemorrhage. Am J Neuroradiology 2001;22:571-6. 


\section{What is already known on this topic}

Lumbar punctures and epidural catheterisations are common, and failed procedures result in loss of diagnostic information or inadequate analgesia

Ultrasound imaging can be used to visualise the relevant anatomy of the spine for these procedures

Many randomised trials have compared ultrasound imaging for these procedures with standard palpation methods, but none has shown a significant effect on the ability to reduce failed procedures

\section{What this study adds}

Ultrasound imaging can reduce the risk of failed lumbar punctures and epidural catheterisations

Ultrasound imaging can also reduce the risk of traumatic procedures and the number of needle insertions and redirection

42 Miksys N, Gordon CL, Thomas K, Connolly BL. Estimating effective dose to pediatric patients undergoing interventional radiology procedures using Anthropomorphic Phantoms and MOSFET dosimeters. Am J Roentgenol 2010;194:1315-22.

43 Sidhu M, Coley B, Goske M, Connolly B, Racadio J, Yoshizumi T, et al. Image gently, step lightly: increasing radiation dose awareness in pediatric interventional radiology. Pediatric Radiology 2009;39:1135-8.

44 Gogalniceanu P, Sheena Y, Kashef E, Purkayastha S, Darzi A, Paraskeva P. Is basic emergency ultrasound training feasible as part of standard undergraduate medical education? J Surg Educ 2010;67:152-6.

45 Rao S, van Holsbeeck L, Musial JL, Parker A, Bouffard JA, Bridge P, et al. A pilot study of comprehensive ultrasound education at the Wayne State University School of Medicine: a pioneer year review. J Ultrasound Med 2008;27:745-9.
46 Hoppman R, Cook T, Hunt P, Folwer S, Paulman L, Wells J, et al. Ultrasound in medical education: a vertical curriculum at the University of South Carolina School of Medicine. J S C Med Assoc 2006;102:330-4.

\section{Accepted: 18 February 2013}

\section{Cite this as: BMJ 2013:346:f1720}

This is an open-access article distributed under the terms of the Creative Commons Attribution Non-commercial License, which permits use, distribution, and reproduction in any medium, provided the original work is properly cited, the use is non commercial and is otherwise in compliance with the license. See: http://creativecommons.org/licenses/bync/2.0/ and http://creativecommons.org/licenses/by-nc/2.0/legalcode. 


\section{Tables}

\begin{tabular}{|c|c|c|c|c|c|c|c|c|c|}
\hline Study & Year & Country & $\mathbf{N}$ & Population & Setting & Procedure & Ultrasound & Operator & Equipment \\
\hline $\mathrm{Grau}^{25}$ & $2001 a$ & Germany & 72 & $\begin{array}{l}\text { Obstetric patients with } \\
\text { presumed or identified } \\
\text { difficult EC }\end{array}$ & LD & EC & Pre-procedure & Staff anaesthetist & $\begin{array}{l}\text { Kretz Sonoace } 6000,5 \\
\text { MHz curved probe }\end{array}$ \\
\hline $\mathrm{Grau}^{26}$ & $2001 b$ & Germany & 80 & $\begin{array}{l}\text { Obstetric patients } \\
\text { scheduled for } \\
\text { caesarean section }\end{array}$ & LD & EC (CSE) & Pre-procedure & Staff anaesthetist & $\begin{array}{l}\text { Kretz Sonoace } 6000,5 \\
\text { MHz curved probe }\end{array}$ \\
\hline $\mathrm{Grau}^{27}$ & 2002 & Germany & 300 & $\begin{array}{l}\text { Obstetric patients } \\
\text { scheduled for vaginal } \\
\text { or caesarean delivery }\end{array}$ & LD & EC & Pre-procedure & Staff anaesthetist & $\begin{array}{l}\text { Kretz Sonoace } 6000,5 \\
\text { MHz curved probe }\end{array}$ \\
\hline $\mathrm{Grau}^{28}$ & 2004 & Germany & 30 & $\begin{array}{l}\text { Obstetric patients } \\
\text { scheduled for } \\
\text { caesarean section }\end{array}$ & LD & EC (CSE) & $\begin{array}{l}\text { Real-time and } \\
\text { Pre-Procedure }\end{array}$ & Staff anaesthetist & $\begin{array}{l}\text { GE Logiq } 400 \text { system, } 7.5 \\
\text { MHz linear probe }\end{array}$ \\
\hline $\begin{array}{l}\text { Pisupati } \\
(\text { abstract) })^{29}\end{array}$ & 2004 & United States & 33 & Adults & ER & LP & Pre-procedure & ER "physician" & $\mathrm{N} / \mathrm{A}$ \\
\hline Willschke $e^{30}$ & 2006 & $\begin{array}{l}\text { Austria and } \\
\text { South Africa }\end{array}$ & 64 & $\begin{array}{l}\text { Children 0-6 years old } \\
\text { undergoing major } \\
\text { surgery }\end{array}$ & OR & $\begin{array}{l}\text { EC (lumbar } \\
\text { or thoracic) }\end{array}$ & Real-time & Staff anaesthetist & $\begin{array}{l}\text { Sonosite } 180 \text { plus, } 5-10 \\
\text { MHz linear probe }\end{array}$ \\
\hline Nomura $^{31}$ & 2007 & United States & 46 & Adults & ER & LP & Pre-procedure & $\begin{array}{l}\text { ER staff or } \\
\text { experienced } \\
\text { residents }\end{array}$ & $\begin{array}{l}\text { Sonosite Titan or } \\
\text { 180plus, multiple probes }\end{array}$ \\
\hline $\mathrm{Lee}^{32}$ & 2008 & Korea & 61 & Adults & ER & LP & Pre-procedure & ER residents & $\begin{array}{l}\text { Sonosite MicroMaxx, 2-5 } \\
\text { MHz curved probe }\end{array}$ \\
\hline $\mathrm{Cho}^{33}$ & 2009 & Korea & 60 & Adults $>60$ years old & ER & LP & Pre-procedure & ER residents & $\begin{array}{l}\text { Sonosite MicroMaxx, 2-5 } \\
\mathrm{MHz} \text { curved probe }\end{array}$ \\
\hline Vallejo $0^{34}$ & 2010 & USA & 370 & Obstetric patients & LD & EC & Pre-procedure & $\begin{array}{l}\text { Junior anaesthesia } \\
\text { residents }\end{array}$ & $\begin{array}{l}\text { Sonosite Micromaxx, } 2-5 \\
\text { MHz curved probe }\end{array}$ \\
\hline Kawaguchi $^{37 *}$ & 2011 & Japan & 24 & $\begin{array}{l}\text { Adults undergoing total } \\
\text { hip arthroplasty }\end{array}$ & OR & $\begin{array}{l}\text { EC } \\
\text { (deliberate } \\
\text { ipsilateral) }\end{array}$ & Pre-procedure & $\begin{array}{l}\text { Two staff } \\
\text { anaesthetists }\end{array}$ & $\begin{array}{l}\text { GE Logiq Book XP, 2-5 } \\
\text { MHz curved probe }\end{array}$ \\
\hline $\mathrm{Chin}^{35}$ & 2011 & Canada & 120 & $\begin{array}{l}\text { Adults undergoing } \\
\text { orthopaedic surgery } \\
\text { with difficult surface } \\
\text { landmarks }\end{array}$ & OR & $\begin{array}{l}\text { LP (spinal } \\
\text { anaesthesia) }\end{array}$ & Pre-procedure & $\begin{array}{l}\text { Anaesthesia staff } \\
\text { or fellows }\end{array}$ & $\begin{array}{l}\text { Sonosite M-Turbo, } 2-5 \\
\text { MHz curved probe }\end{array}$ \\
\hline $\begin{array}{l}\text { Gnaho } \\
\text { (abstract) })^{36}\end{array}$ & 2011 & France & 20 & $\begin{array}{l}\text { Obese obstetric } \\
\text { patients }\end{array}$ & LD & EC & Real-time & $\begin{array}{l}\text { Anaesthesia } \\
\text { "physicians" }\end{array}$ & $\begin{array}{l}\text { Logiq book xppro GE } \\
\text { Solingen, } 5 \mathrm{MHz} \text { curved } \\
\text { probe }\end{array}$ \\
\hline $\begin{array}{l}\text { Fogel } \\
\text { (abstract) }^{38 *}\end{array}$ & 2011 & United States & 54 & Obstetric patients & LD & EC & Pre-procedure & $\begin{array}{l}\text { Anaesthesia staff, } \\
\text { residents, and } \\
\text { CRNAs }\end{array}$ & $\begin{array}{l}\text { Sonosite M-Turbo, } 2-5 \\
\text { MHz curved probe }\end{array}$ \\
\hline
\end{tabular}

$C R N A=$ certified registered nurse anaesthetist; $C S E=$ combined spinal-epidural anaesthesia; $E C=$ epidural catheterisations; $E R=e m e r g e n c y$ room; $L D=$ labour and delivery suite; $\mathrm{LP}=$ lumbar puncture; $\mathrm{MHz}=$ megahertz; $\mathrm{N}=$ no of patients; $\mathrm{N} / \mathrm{A}=$ not available; $\mathrm{OR}=$ operating room.

*Additional information provided by authors. 


\begin{tabular}{|c|c|c|c|c|c|c|c|}
\hline Study & $\begin{array}{l}\text { Sequence } \\
\text { generation }\end{array}$ & Concealment & Blinding & Outcome reporting & $\begin{array}{l}\text { Intervention } \\
\text { details }\end{array}$ & $\begin{array}{c}\text { Experience and } \\
\text { skill }\end{array}$ & $\begin{array}{l}\text { Different operators } \\
\text { in each group }\end{array}$ \\
\hline Grau $2001 a^{25}$ & Unclear & Adequate & Inadequate & Adequate & Adequate & Adequate & Inadequate \\
\hline Grau $2001 b^{26}$ & Unclear & Adequate & Inadequate & Adequate & Adequate & Adequate & Inadequate \\
\hline Grau $2002^{27}$ & Unclear & Adequate & Inadequate & Adequate & Adequate & Adequate & Inadequate \\
\hline Grau $2004^{28}$ & Unclear & Adequate & Inadequate & Adequate & Adequate & Adequate & Inadequate \\
\hline Pisupati $2004^{29}$ & Unclear & Adequate & Inadequate & Adequate & Adequate & Adequate & Unclear \\
\hline Willschke $2006^{30}$ & Adequate & Adequate & Inadequate & Adequate & Adequate & Adequate & Unclear \\
\hline Nomura $2007^{31}$ & Adequate & Adequate & Adequate & Adequate & Adequate & Adequate & Adequate \\
\hline Lee $2008^{32}$ & Unclear & Adequate & Inadequate & Inadequate & Adequate & Inadequate & Unclear \\
\hline Cho $2009^{33}$ & Unclear & Adequate & Inadequate & Adequate & Adequate & Inadequate & Unclear \\
\hline Vallejo $2010^{34}$ & Adequate & Adequate & Inadequate & Adequate & Adequate & Inadequate & Adequate \\
\hline Kawaguchi $2011^{37}$ & Adequate & Adequate & Inadequate & Adequate & Adequate & Adequate & Inadequate \\
\hline Chin $2011^{35}$ & Adequate & Adequate & Inadequate & Adequate & Adequate & Adequate & Adequate \\
\hline Gnaho $2011^{36}$ & Unclear & Unclear & Unclear & Adequate & Unclear & Unclear & Unclear \\
\hline Fogel $2011^{38}$ & Adequate & Adequate & Inadequate & Adequate & Adequate & Adequate & Inadequate \\
\hline K $(95 \% \mathrm{Cl})$ & 0.55 (0.11 to 0.99$)$ & $0.76(0.32$ to 1.00$)$ & $1.0(1.0$ to 1.0$)$ & 0.63 (0.0 to 1.0$)$ & $0.76(0.32$ to 1.0$)$ & $0.70(0.32$ to 1.0$)$ & $0.76(0.32$ to 1.0$)$ \\
\hline
\end{tabular}


Table 3| Summary of outcomes for ultrasound imaging groups versus control groups

\begin{tabular}{|c|c|c|c|}
\hline & Effect $(95 \% \mathrm{Cl})$ & $\mathbf{P}$ & $I^{2}(\%)$ \\
\hline \multicolumn{4}{|c|}{ No of failed procedures (12 studies) } \\
\hline Risk ratio & 0.21 (0.10 to 0.43$)$ & $<0.001$ & 0 \\
\hline Absolute risk reduction & 0.063 (0.041 to 0.084$)$ & - & - \\
\hline Number needed to treat & 16 (12 to 25$)$ & - & - \\
\hline \multicolumn{4}{|c|}{ No of traumatic procedures (5 studies) } \\
\hline Risk ratio & 0.27 (0.11 to 0.67$)$ & 0.005 & 0 \\
\hline Absolute risk reduction & $0.059(0.023$ to 0.095$)$ & - & - \\
\hline Number needed to treat & $17(11$ to 44$)$ & - & - \\
\hline \multicolumn{4}{|c|}{ No of insertion attempts ( 8 studies) } \\
\hline Mean difference & $-0.44(-0.64$ to -0.24$)$ & $<0.001$ & 73 \\
\hline \multicolumn{4}{|c|}{ No of needle redirections (8 studies) } \\
\hline Mean difference & $-1.00(-1.24$ to -0.75$)$ & $<0.001$ & 69 \\
\hline
\end{tabular}




\begin{tabular}{|c|c|c|c|c|c|}
\hline \multicolumn{6}{|c|}{ Table 4| Subgroup analyses } \\
\hline \multirow[b]{2}{*}{ Outcome } & \multicolumn{2}{|r|}{ Subgroup 1} & \multicolumn{2}{|r|}{ Subgroup 2} & \multirow{2}{*}{$\begin{array}{l}P \text { for } \\
\text { interaction }\end{array}$} \\
\hline & No of studies & Effect $(95 \% \mathrm{Cl})$ & No of studies & Effect $(95 \% \mathrm{Cl})$ & \\
\hline \multicolumn{6}{|c|}{ Lumbar punctures $v$ epidural catheterisations } \\
\hline Failed procedures & 5 & $\begin{array}{c}\text { RR } 0.19 \text { (0.07 to } 0.56) \text {, ARR } 0.12 \\
\text { NNT } 9\end{array}$ & 7 & $\begin{array}{c}\text { RR } 0.23 \text { (0.09 to } 0.60) \text {, ARR } 0.04 \\
\text { NNT } 25\end{array}$ & 0.92 \\
\hline Traumatic procedures & 2 & $\begin{array}{c}\text { RR } 0.24 \text { (0.05 to } 1.08) \text {, ARR 0.11, } \\
\text { NNT } 9\end{array}$ & 3 & $\begin{array}{c}\text { RR } 0.28 \text { (0.09 to } 0.92) \text {, ARR 0.04, } \\
\text { NNT } 24\end{array}$ & 0.99 \\
\hline Insertion attempts & 3 & $M D-1.01(-1.56$ to -0.45$)$ & 5 & $\mathrm{MD}-0.23(-0.33$ to 0.13$)$ & 0.007 \\
\hline \multicolumn{6}{|c|}{ Procedure performed by emergency physician $v$ anaesthetist } \\
\hline Failed procedures & 4 & $\begin{array}{c}\text { RR } 0.15 \text { (0.05 to } 0.50) \text {, ARR } 0.17 \\
\text { NNT } 6\end{array}$ & 8 & $\begin{array}{c}\text { RR } 0.25 \text { (0.10 to } 0.62) \text {, ARR 0.04, } \\
\text { NNT } 25\end{array}$ & 0.51 \\
\hline Traumatic procedures & 2 & $\begin{array}{c}\text { RR } 0.24 \text { (0.05 to } 1.08) \text {, ARR 0.11, } \\
\text { NNT } 10\end{array}$ & 3 & $\begin{array}{c}\text { RR } 0.28 \text { (0.09 to } 0.92) \text {, ARR 0.04, } \\
\text { NNT } 24\end{array}$ & 0.86 \\
\hline Insertion attempts & 2 & MD $-1.22(-2.29$ to -0.14$)$ & 6 & MD $-0.33(-0.49$ to -0.17$)$ & 0.11 \\
\hline \multicolumn{6}{|c|}{ Treatment groups had same operator or unclear information $v$ different operators or adequate blinding } \\
\hline Failed procedures & 9 & $\begin{array}{c}\text { RR } 0.16 \text { (0.06 to } 0.45) \text {, ARR } 0.07 \text {, } \\
\text { NNT } 14\end{array}$ & 3 & $\begin{array}{c}\text { RR } 0.27 \text { ( } 0.10 \text { to } 0.73) \text {, ARR } 0.05 \text {, } \\
\text { NNT } 20\end{array}$ & 0.46 \\
\hline Redirection attempts & 6 & MD $-0.95(-1.19$ to -0.70$)$ & 2 & MD $-3.74(-9.60$ to 2.12$)$ & 0.35 \\
\hline \multicolumn{6}{|c|}{ Low $v$ high experience of operators } \\
\hline Failed procedures & 3 & $\begin{array}{c}\text { RR } 0.22 \text { (0.08 to } 0.61), \text { ARR } 0.07 \\
\text { NNT } 14\end{array}$ & 9 & $\begin{array}{c}\text { RR } 0.20 \text { (0.07 to } 0.55) \text {, ARR 0.06, } \\
\text { NNT } 17\end{array}$ & 0.88 \\
\hline Traumatic procedures & 2 & $\begin{array}{c}\text { RR } 0.24 \text { (0.05 to } 1.08) \text {, ARR 0.11, } \\
\text { NNT } 9\end{array}$ & 3 & $\begin{array}{c}\text { RR } 0.28 \text { (0.09 to } 0.92), \text { ARR 0.04, } \\
\text { NNT } 24\end{array}$ & 0.99 \\
\hline Insertion attempts & 2 & $\mathrm{MD}-1.22(-2.29$ to -0.14$)$ & 6 & $\mathrm{MD}-0.33(-0.48$ to -0.17$)$ & 0.11 \\
\hline \multicolumn{6}{|c|}{ Patients selected for presumed difficult procedures $v$ unselected patients } \\
\hline Failed procedures & 4 & $\begin{array}{c}\text { RR } 0.22 \text { (0.06 to } 0.88) \text {, ARR 0.09, } \\
\text { NNT } 11\end{array}$ & 8 & $\begin{array}{c}\text { RR } 0.21 \text { (0.09 to } 0.48) \text {, ARR 0.06, } \\
\text { NNT } 17\end{array}$ & 0.92 \\
\hline Insertion attempts & 3 & MD $-0.81(-1.52$ to -0.11$)$ & 5 & MD $-0.27(-0.41$ to -0.13$)$ & 0.14 \\
\hline Redirection attempts & 2 & MD $-3.65(-9.71$ to 2.41$)$ & 6 & MD $-0.99(-1.19$ to -0.79$)$ & 0.39 \\
\hline
\end{tabular}

$\mathrm{ARR}=$ absolute risk reduction; $\mathrm{NNT}=$ number needed to treat; $\mathrm{RR}=$ risk ratio; $\mathrm{MD}=$ mean difference.

Subgroup analyses were performed for outcomes where more than one study with an estimable effect was available per subgroup. 


\section{Figures}

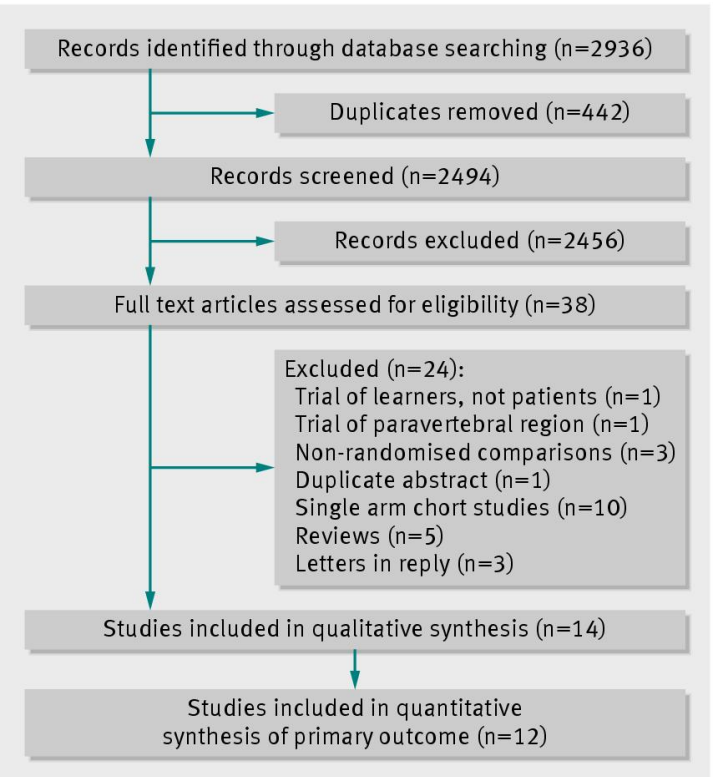

Fig 1 PRISMA flow diagram showing progress of trials

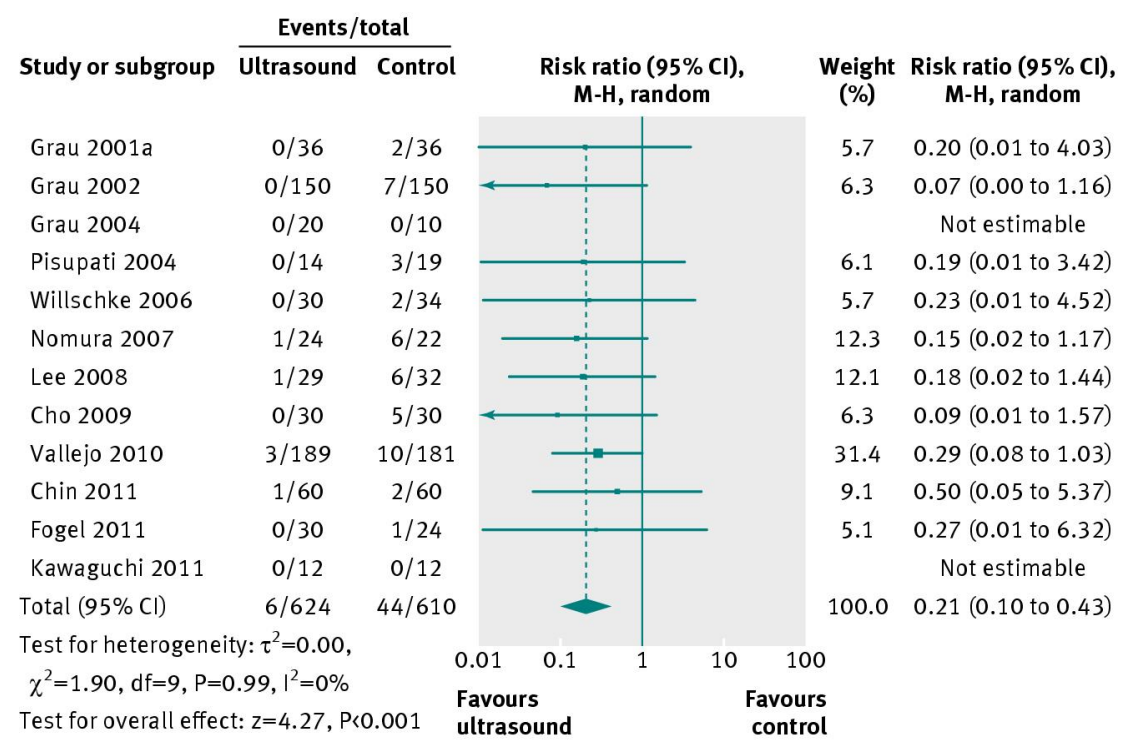

Fig 2 Risk of failed procedures in ultrasound versus control groups. Squares to the left of the vertical line indicate that ultrasound reduced the risk of a failed procedure; horizontal lines $=95 \%$ confidence intervals; square size=each study's relative weight; diamond=aggregate relative risk (95\% confidence interval); $\mathrm{M}-\mathrm{H}=$ Mantel-Haenszel 